This item was submitted to Loughborough's Research Repository by the author.

Items in Figshare are protected by copyright, with all rights reserved, unless otherwise indicated.

\title{
Influence of prolonged treadmill running on appetite, energy intake and circulating concentrations of acylated ghrelin
}

PLEASE CITE THE PUBLISHED VERSION

http://dx.doi.org/10.1016/j.appet.2010.02.002

PUBLISHER

(C) Elsevier Ltd.

VERSION

AM (Accepted Manuscript)

LICENCE

CC BY-NC-ND 4.0

\section{REPOSITORY RECORD}

King, James A., Masashi Miyashita, Lucy K. Wasse, and David J. Stensel. 2019. "Influence of Prolonged Treadmill Running on Appetite, Energy Intake and Circulating Concentrations of Acylated Ghrelin". figshare. https://hdl.handle.net/2134/10163. 
This item was submitted to Loughborough's Institutional Repository (https://dspace.lboro.ac.uk/) by the author and is made available under the following Creative Commons Licence conditions.

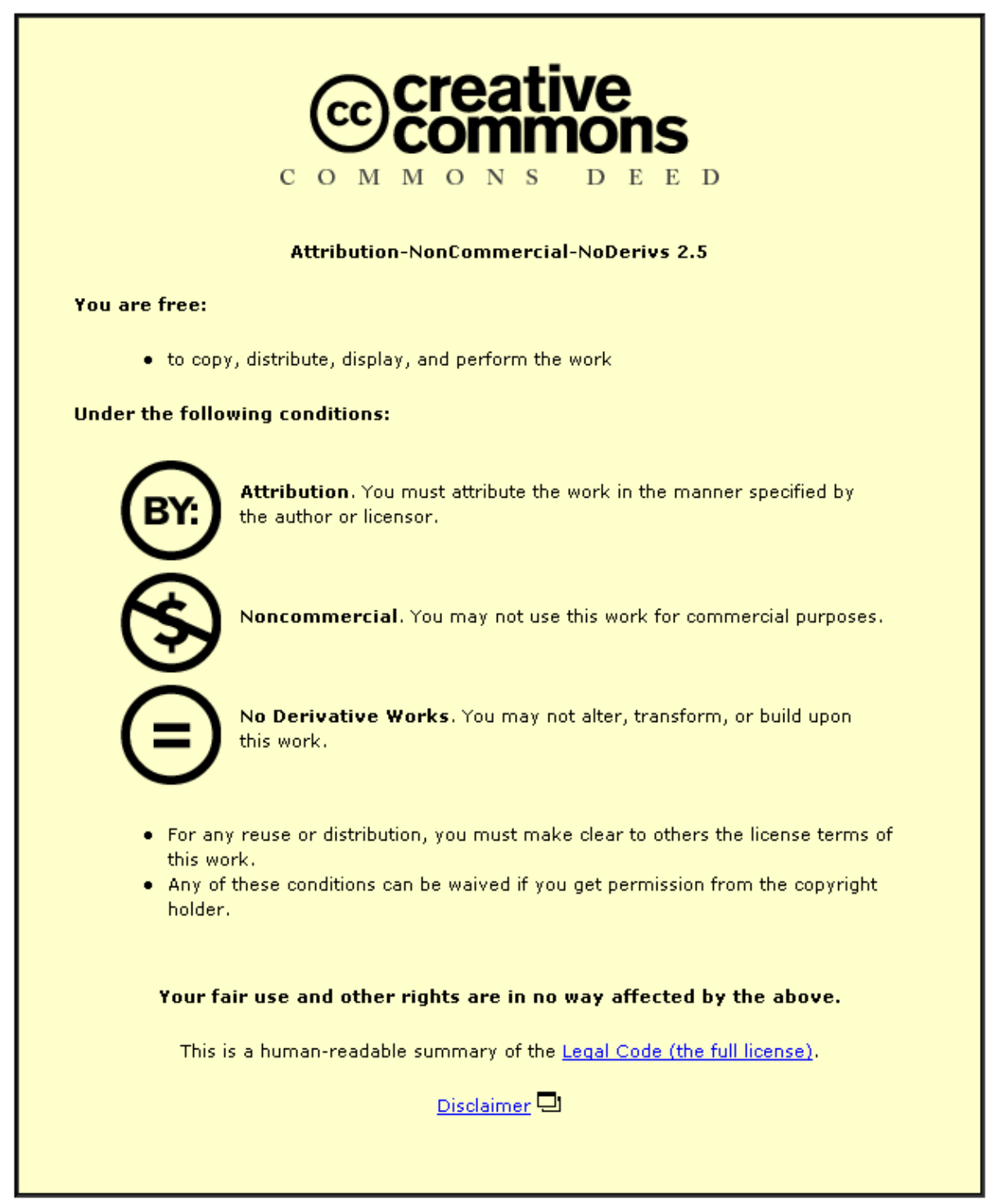

For the full text of this licence, please go to: http://creativecommons.org/licenses/by-nc-nd/2.5/ 


\section{Elsevier Editorial System(tm) for Appetite Manuscript Draft}

Manuscript Number: APPETITE-D-09-00302R1

Title: Influence of prolonged treadmill running on appetite, energy intake and circulating concentrations of acylated ghrelin

Article Type: Full length paper

Keywords: Exercise, acylated ghrelin, appetite, energy intake, energy balance, compensation.

Corresponding Author: Dr David John Stensel, PhD

Corresponding Author's Institution: Loughborough University

First Author: James A King, BSc

Order of Authors: James A King, BSc; Masashi Miyashita, PhD; Lucy K Wasse, MSc; David J Stensel, PhD

Abstract: The effects of prolonged treadmill running on appetite, energy intake and acylated ghrelin (an appetite stimulating hormone) were examined in 9 healthy males over the course of $24 \mathrm{~h}$.

Participants completed 2 experimental trials (exercise and control) in a randomised - crossover fashion. In the exercise trial participants ran for $90 \mathrm{~min}$ at $68.8 \pm 0.8 \%$ of maximum oxygen uptake followed by $8.5 \mathrm{~h}$ of rest. Participants returned to the laboratory on the following morning to provide a fasting blood sample and ratings of appetite ( $24 \mathrm{~h}$ measurement). No exercise was performed on the control trial. Appetite was measured within the laboratory using visual analogue scales and energy intake was assessed from ad libitum buffet meals. Acylated ghrelin was determined from plasma using an ELISA assay. Exercise transiently suppressed appetite and acylated ghrelin but each remained no different from control values in the hours afterwards. Furthermore, despite participants expending $5324 \mathrm{~kJ}$ during exercise there was no compensatory increase in energy intake ( $24 \mathrm{~h}$ energy intake; control $17191 \mathrm{~kJ}$, exercise $17606 \mathrm{~kJ}$ ). These findings suggest that large energy deficits induced by exercise do not lead to acute compensatory responses in appetite, energy intake or acylated ghrelin. 
Professor H.R Bertoud

Louisiana State University

Baton Rouge

LA

USA

Dear Professor Berthold,

Thank you for inviting us to re-submit our paper to be considered for publication in Appetite. We have carefully considered the comments from the reviewers and have formulated responses to the points raised. Our responses, and the necessary changes (highlighted in yellow) are included within the revised document. We thank you once more for considering our manuscript and we look forward to hearing from you in due course.

Yours sincerely,

David Stensel, $\mathrm{PhD}$

Senior Lecturer

Director of Postgraduate Studies

School of Sport, Exercise and Health Sciences

Loughborough University

Leicestershire

LE11 3TU

Direct line 01509226344

E-mail D.J.Stensel@lboro.ac.uk

http://www.lboro.ac.uk/departments/ssehs/ 
We thank each reviewers for reading our paper and for their constructive comments. We feel that we can adequately address the issues raised by each reviewer therefore, in an effort to do so, below we have listed the comments from each reviewer followed by our responses.

\section{Reviewer \# 1 comment 1}

Studies on exercise and compensation in the short term have already taken place and have shown no compensation in energy intake once REI is calculated; therefore what is the rationale for undertaking this study, and for the particular hypothesis?

\section{Response to comment of the reviewer}

Reviewer \#1 is quite right, studies to date have shown no compensation in energy intake after accounting for relative energy intake (REI). However, previous studies have not induced such a large energy deficit during a single bout of exercise. Moreover, previous studies have not examined appetite and energy intake responses over such a long period of time under controlled conditions. Most studies in this area have examined energy intake responses at a single meal within one or two hours after exercise. It is possible that compensation may occur over a longer duration, at a second, third or fourth meal taken after completing exercise. In addition to this, previous studies have not examined the potential role of ghrelin in mediating appetite and energy intake responses over this extended duration. It has been shown that ghrelin is sensitive to acute changes in energy balance induced through dietary means, therefore we were keen to assess whether ghrelin would compensate for energy deficits induced through exercise and to examine the potential effects on appetite and energy intake.

We agree that we could have made the rationale for our hypothesis clearer. To address this issue we have re-written the final paragraph in our introduction so that this is made more explicit.

\section{Reviewer \# 1 comment 2}

By using fit well-trained athletes, the exercise regime may not be an unusual intervention, and the likelihood of compensation would be diminished. What is the relevance of these findings for similar exercise in overweight/obese subjects?

\section{Response to comment of the reviewer}

The participants in this study were young, healthy individuals who were relatively fit by population standards but were not athletes. This is reflected by the mean maximum oxygen uptake value for the group $\left(60.5 \mathrm{ml} \cdot \mathrm{kg}^{-1} \cdot \mathrm{min}^{-1}\right)$. Participants were recreationally active, tending to be games players (soccer, hockey and rugby) training/playing games 2 or 3 times per week. These individuals were most certainly not accustomed to performing such prolonged bouts of activity with the consequent level of energy expenditure. We therefore believe that the exercise bout completed would have posed a novel challenge to energy homeostasis in this group of individuals. 
The findings that we have reported are not immediately relevant to overweight or obese individuals as it is unlikely that they would be able to complete such an exercise challenge. This was not the aim however as the protocol was intended to be physically challenging so as to perturb energy homeostasis. Initial findings from studies such as these can provide useful information and form the basis for further research in different populations. A recent investigation (cited in our references) observed a suppression of acylated ghrelin during peak exercise in lean and obese subjects and the suppression was more marked in obese than in the lean subjects (Marzullo et al, 2008). Circulating concentrations of ghrelin tend to be lower in obese individuals therefore we cannot be sure that our findings would generalise to an obese group. We think that examining ghrelin, and other gut hormone responses to exercise in overweight and obese groups, is an important avenue for future research.

\section{Reviewer \# 1 comment 3, 4, 5 and 6}

(Comment 3) In the abstract it is mentioned that 'exercise transiently suppressed appetite' but these data are not shown and do not appear in Fig 1. Also the icon depicting the meal suggest the meal lasted for 1 hour, whereas in the methods it states that the meal was given for $30 \mathrm{~min}$.

(Comment 4) Hunger also seems to increase, and fullness decrease, during the meal on the exercise trial. What could be the reason for these strange results?

(Comment 5) Fig 1 - what is VLR? Not explained in the legend or the text.

(Comment 6) There is a lack of correspondence between the appetite variables (Fig 1) and the Blood profiles which does not help interpretation. It would be helpful if the profiles could cover the same time intervals.

Response to comments of the reviewer

We can only apologise for what has led to the issues raised in comments 3, 4, 5 and 6 . On receipt of these comments we have realised that in the manuscript submitted the file that was attached as Figure 1 was not the correct file. Again, we are sorry for the confusion which this has caused. In this revised manuscript we have amended this error by attaching the correct file.

Consequently, in response to comment 3 - the transient suppression in appetite during exercise can now be observed in Figure 1. Also, it is now clear that the meal lasts 30 min and not $1 \mathrm{~h}$.

In response to comment 4 - changes in each of the appetite markers assessed (hunger, fullness, satisfaction and prospective food consumption) respond in a co-ordinated and logical manor.

In response to comment 5 - the VLR abbreviation does not apply to this study and therefore is not shown in the amended figure. 
In response to comment 6 - the $\mathrm{x}$ axis (time) on the amended figure spans the full 24 $\mathrm{h}$ of the trial precisely as in the figures showing data for acylated ghrelin, glucose, insulin and triacylglycerol.

\section{Reviewer \#1 comment 7}

The use of trained athletes who are accustomed to training at this intensity (I assume) probably means that they have a strong habitual dietary routine (most athletes in training behave like this). Would this tight control over eating habits prevent any impact of the exercise training on eating?

\section{Response to comment of the reviewer}

As mentioned in response to comment 2, although the participants in this study were young, healthy and fit they were only recreationally active and they were not trained athletes. They certainly did not perform 90 minute runs on a regular basis and most of the participants found this exercise very challenging. We therefore feel that this was a relatively novel exercise bout for these participants although we accept that different results may occur when studying very sedentary individuals. Having said this, very sedentary individuals would not be able to perform such vigorous and prolonged exercise so we do feel that the model we have employed is a good one for testing appetite and acylated ghrelin responses to a large exercise-induced energy deficit.

\section{Reviewer \# 2 comment 1}

In the discussion, page 15, the authors should state that another notable limitation of this study is the low number of patients.

\section{Response to comment of the reviewer}

This limitation of the study has now been added within the discussion section (see the first line of paragraph 2 on page 17).

\section{Reviewer \# 2 comment 2}

Table 3, please indicate $\mathrm{P}$ values in the table

Response to comment of the reviewer

$\mathrm{P}$ values have now been added to the data shown in Table 3

\section{Reviewer \# 2 comment 3}

The authors should describe clearly how acetyl ghrelin levels were measured (company, etc). Unless I missed it, this information is not in material and methods. 
Response to comment of the reviewer

A biochemical analysis section has now been added to the methods which details this information (see page 8 ). 
Influence of prolonged treadmill running on appetite, energy intake and circulating concentrations of acylated ghrelin

James A King ${ }^{1}$, Masashi Miyashita ${ }^{2}$, Lucy K Wasse ${ }^{1}$ and David J Stensel ${ }^{1}$

1 Exercise and Health Research Group, School of Sport, Exercise and Health Sciences, Loughborough University, UK

2 Division of Sports Medicine, Graduate School of Comprehensive Human Science, University of Tsukuba, Japan

\section{Running Title}

Acylated ghrelin, appetite, exercise

\section{Correspondence}

Dr David Stensel

School of Sport, Exercise and Health Sciences

Loughborough University

Leicestershire

LE11 3TU

UK

Phone: +44(0)1509 226344

Fax: $\quad+44(0) 1509226301$

E-mail: D.J.Stensel@lboro.ac.uk

\section{Disclosures}

MM received a research donation from the Great Britain Sasakawa Foundation. 
Word Count

4354 


\begin{abstract}
The effects of prolonged treadmill running on appetite, energy intake and acylated ghrelin (an appetite stimulating hormone) were examined in 9 healthy males over the course of $24 \mathrm{~h}$. Participants completed 2 experimental trials (exercise and control) in a randomised - crossover fashion. In the exercise trial participants ran for 90 min at 68.8 $\pm 0.8 \%$ of maximum oxygen uptake followed by $8.5 \mathrm{~h}$ of rest. Participants returned to the laboratory on the following morning to provide a fasting blood sample and ratings of appetite (24 h measurement). No exercise was performed on the control trial. Appetite was measured within the laboratory using visual analogue scales and energy intake was assessed from ad libitum buffet meals. Acylated ghrelin was determined from plasma using an ELISA assay. Exercise transiently suppressed appetite and acylated ghrelin but each remained no different from control values in the hours afterwards. Furthermore, despite participants expending 5324 kJ during exercise there was no compensatory increase in energy intake (24 h energy intake; control $17191 \mathrm{~kJ}$, exercise $17606 \mathrm{~kJ})$. These findings suggest that large energy deficits induced by exercise do not lead to acute compensatory responses in appetite, energy intake or acylated ghrelin.
\end{abstract}

Key words: Exercise, acylated ghrelin, appetite, energy intake, energy balance, compensation. 


\section{Introduction}

The global prevalence of overweight and obesity continues to rise and provokes a need to find efficacious interventions to combat this problem (Kelly, Yang, Chen, Reynolds, $\& \mathrm{He}, 2008)$. Exercise is effective at preventing weight gain and maintaining a reduced body weight following weight loss however in the absence of a calorie restricted diet the ability of exercise to induce weight loss is less certain (Catenacci \& Wyatt, 2007; Donnelly et al, 2009; Seagle et al, 2009). A possible explanation for this is that exercise may elicit compensatory increases in appetite and energy intake, responses that would negate the ability to induce a sustained energy deficit (King et al, 2007).

Findings regarding the acute influence of exercise on appetite are mixed with reports of no change in appetite along with both increases and decreases (Blundell, Stubbs, Hughes, Whybrow, \& King, 2003; Martins, Morgan, \& Truby, 2008). Such diversity has also been described with regards to the acute influence of exercise on energy intake (Blundell \& King, 1999; Maraki et al, 2005). The inconsistency in findings likely reflects dissimilarity in study protocols and participant characteristics. Within this area of enquiry recent efforts have sought to find the mechanisms responsible for alterations in appetite during and after exercise. Peptides secreted from the gastrointestinal tract such as cholecystokinin, peptide YY, glucagon like peptide 1 and ghrelin mediate shortterm feelings of hunger and satiety, therefore recent interest has focused on the response of these hormones to exercise (Broom, Stensel, Bishop, Burns, \& Miyashita, 2007; Broom, Batterham, King, \& Stensel, 2009; Martins, Morgan, Bloom, \& Robertson, 2007; Ueda et al, 2009). 
Of the peptides regulating energy balance ghrelin is conspicuous as the only known peptide that stimulates appetite and food intake - all others act as satiety signals reducing appetite and promoting meal termination (Murphy \& Bloom, 2006). A well defined role of ghrelin in the regulation of energy homeostasis exists with circulating values being sensitive to both acute (Callahan et al, 2004; Leidy \& Williams, 2006; Liu et al, 2008) and chronic (Cummings, 2006; Leidy, Dougherty, Frye, Duke, \& Williams, 2007) perturbations in energy balance. Exercise influences energy balance therefore it is possible that exercise may influence ghrelin. The acute influence of exercise on ghrelin has received significant interest (Kraemer \& Castracane, 2007) however the majority of studies have assessed circulating total ghrelin concentrations rather than acylated ghrelin, the post-translationally modified peptide that assumes sole responsibility for appetite stimulation (Broglio et al, 2004). Four studies have assessed the acute effect of exercise on acylated ghrelin (Broom et al, 2007; 2009; Marzullo et al, 2008; Ueda et al, 2009). Findings from these studies suggest that high intensity exercise suppresses circulating concentrations of acylated ghrelin.

In the present investigation we sought to examine prolonged appetite, energy intake and acylated ghrelin responses to an acute bout of exercise, sufficient to induce a substantial energy deficit. Previous studies within this area have tended to assess appetite and energy intake responses at a single meal presented shortly after exercise but it is possible that changes may occur over a longer duration, at a second, third or fourth meal taken after completing exercise. Moreover, we sought to determine whether a large perturbation to energy balance would be associated with a compensatory increase in circulating concentrations of acylated ghrelin as a signal to augment appetite and subsequent energy intake. It has been shown that ghrelin is sensitive to acute changes in 
energy balance in response to dietary manipulation (Leidy and Williams, 2006) therefore we wanted to assess if circulating concentrations of acylated ghrelin would be elevated in the hours after an extended bout of exercise as a means to stimulate compensatory increases in appetite and energy intake. 


\section{Methods}

\section{Participants}

Following university ethical committee approval nine healthy male volunteers $(18-27$ y) gave written informed consent to participate. Participants were non-smokers, free of cardiovascular/metabolic disease, not taking medication and not obese (BMI $\leq 29.9$ kg. $\mathrm{m}^{-2}$ ) or hypertensive (blood pressure $<140 / 90 \mathrm{mmHg}$ ). Table 1 describes the participant characteristics.

(Insert Table 1 near here)

\section{Screening and familiarisation}

Prior to main trials participants visited the laboratory to complete questionnaires assessing food preferences, health status, habitual physical activity and dietary habits. Thereafter, height was measured to the nearest $0.1 \mathrm{~cm}$ using a stadiometer (Seca Ltd, Germany) and body weight was measured to the nearest $0.01 \mathrm{~kg}$ using a balance beam scale (Avery Industrial Ltd., Leicester, UK.). Body mass index (BMI) was subsequently calculated. Subcutaneous skinfold measurements were made (Durnin \& Wormersley, 1974) to estimate percentage body fatness (Siri, 1956).

\section{Exercise Tests}

To determine the individual relationship between running speed and oxygen consumption participants completed a 16 min submaximal treadmill running test on a level motorised treadmill (RUNRACE, Techno gym, Gambettola, Italy). The treadmill speed began at 8-9 km.h ${ }^{-1}$ and was increased by $1-1.5 \mathrm{~km} \cdot \mathrm{h}^{-1}$ following the completion of each 4 min stage. Oxygen consumption and carbon dioxide production were 
determined from expired air collections taken in the final min of each stage (Frayn, 1983). After sufficient rest maximum oxygen uptake was assessed using an exhaustive treadmill running test as previously described (Taylor, Buskirk, \& Henschel, 1955).

\section{Main trials}

Participants completed two, $24 \mathrm{~h}$ trials (exercise and control) in a randomised-repeated measures design with trials being separated by at least one-week. Trials began in the morning of day 1 ( 09:00) following a $10 \mathrm{~h}$ overnight fast and participants were confined to the laboratory for the subsequent $10 \mathrm{~h}$. Participants left the laboratory after this period and returned the next morning having fasted from 23:00 the prior evening to provide a blood sample and ratings of appetite (24 $\mathrm{h}$ measurement). During the laboratory phase of trials appetite perceptions (hunger, satisfaction, fullness and prospective food consumption) were assessed at baseline and at $30 \mathrm{~min}$ intervals throughout using $100 \mathrm{~mm}$ visual analogue scales (Flint, Raben, Blundell, \& Astrup, 2000).

The exercise trial began with a 90 min run on a level treadmill at a speed predicted to elicit $70 \%$ of maximum oxygen uptake. Samples of expired air were collected at $15 \mathrm{~min}$ intervals to monitor the intensity of the run. Adjustments were made to the treadmill speed if necessary. During exercise heart rate was assessed using short-range telemetry (Sports tester $\mathrm{PE}_{3000}$, Polar Electro, Finland) and ratings of perceived exertion (Borg, 1973) were determined. After the run participants rested for $8.5 \mathrm{~h}$ (sitting reading, working at a computer or watching television) within the laboratory. Identical procedures were completed during the control trial except participants rested within the laboratory for the entire duration. In the first $90 \mathrm{~min}$ of the control trial samples of 
expired air were collected in order to estimate resting metabolic rate. This permitted the calculation of net energy expenditure during exercise.

\section{Ad libitum buffet meals}

During the laboratory phase on the first trial day participants consumed food from $a d$ libitum buffet meals provided at three time points throughout. Cold buffet meals were offered at 2.5 and $9 \mathrm{~h}$ (Appendix A) and a hot meal was offered at $5.5 \mathrm{~h}$ (Appendix B). Food was available for 30 minutes. In the time spent away from the laboratory inbetween visits on days one and two participants were free to select, and subsequently consume if desired, any items presented at the cold buffet meal. Participants were permitted to consume these items after leaving the laboratory on day one until 23:00 prior to fasting. During preliminary screening acceptability of the buffet food items was ensured by the completion of a food preference questionnaire. At each meal food was presented in excess of expected consumption. Participants were told to eat until satisfied and that additional food was available if desired. Meals were consumed in isolation so that social influence did not affect food selection. Food consumption was ascertained by examining the weighted difference in food items remaining compared to that initially presented. The energy and macronutrient content of the items consumed was ascertained using manufacturer values.

\section{Physical activity and dietary standardization}

Participants completed a weighed food record of all items consumed within the $24 \mathrm{~h}$ preceding their first main trial. Alcohol and caffeine were not permitted during this period. This feeding pattern was replicated prior to successive main trials. Participants 
refrained from strenuous physical activity in the $24 \mathrm{~h}$ preceding main trials and also during the interval between laboratory visits on day one and two.

\section{Blood sampling}

On the first day of trials venous blood was collected via a cannula (Venflon, Becton Dickinson, Helsinborg, Sweden) inserted into an antecubital vein. Venepuncture was used to collect the $24 \mathrm{~h}$ blood sample on the second trial day. Venous blood samples were taken into pre-chilled $4.9 \mathrm{~mL}$ monovettes (Sarstedt, Leicester, UK) at baseline, $0.75,1.5,2,2.5,3.5,5.5,6.5,7.5,9,10$ and $24 \mathrm{~h}$ to measure plasma acylated ghrelin. To prevent the degradation of acylated ghrelin these monovettes contained EDTA and a 50 $\mu \mathrm{L}$ solution containing Potassium Phosphate Buffer (PBS), $P$-Hydroxymercuribenzoic Acid (PHMB) and Sodium Hydroxide (NaOH). Monovettes were spun at $1287 \mathrm{~g}$ for 10 min in a refrigerated centrifuge at $4{ }^{\circ} \mathrm{C}$. The plasma supernatant was then dispensed into a storage tube. Samples were then acidified with $100 \mu \mathrm{L}$ of $1 \mathrm{M}$ hydrochloric acid per millilitre of plasma. Thereafter, samples were spun at $1287 \mathrm{~g}$ for $5 \mathrm{~min}$ in a refrigerated centrifuge prior to storage. For the determination of plasma glucose, insulin and triacylglycerol additional samples were collected into pre-chilled $9 \mathrm{~mL}$ EDTA monovettes (Sarstedt, Leicester, UK) at baseline, 0, 1.5, 2.5, 3, 3.5, 5.5, 6, 6.5, 9, 9.5, 10 and $24 \mathrm{~h}$. The EDTA monovettes were spun at $1681 \mathrm{~g}$ for $10 \mathrm{mins}$ in a refrigerated centrifuge (Bukard, Hertfordshire, U.K.) at $4{ }^{\circ} \mathrm{C}$. The plasma supernatant was then aliquoted into $2 \mathrm{~mL}$ Eppendorf tubes prior to storage for analysis later.

All samples were collected in the semi-supine position except for the $0.75 \mathrm{~h}$ sample during exercise whereby participants straddled the treadmill. For samples collected using a cannula patency was maintained by flushing with non-heparinised saline $(0.9 \%$ 
w/v Sodium Chloride, Baxter Healthcare Ltd., Norfolk, UK). Residual saline was discarded using a $2 \mathrm{~mL}$ syringe prior to sample collection. To estimate changes in plasma volume (Dill \& Costill, 1974) duplicate $20 \mu \mathrm{L}$ blood samples were collected into micropipettes and triplicate $20 \mu \mathrm{L}$ blood samples were collected into heparinised microhaematocrit tubes to determine blood haemoglobin and haematocrit concentration, respectively.

\section{Biochemical Analysis}

An enzyme immunoassay was used to determine concentrations of plasma acylated ghrelin (SPI BIO, Montigny le Bretonneux, France) and insulin (Mercodia, Uppsala, Sweden) with the aid of a plate reader (Expert Plus, ASYS Atlantis, Eugendorf, Austria). Plasma glucose and triacylglycerol concentrations were determined by enzymatic, colorimetric methods using a bench top analyzer (Pentra 400, HORIBA ABX Diagnostics, Montpellier, France). To eliminate inter-assay variation, samples from each participant were analyzed in the same run. The within batch coefficients of variation for the assays were as follows: acylated ghrelin $7.8 \%$, insulin $2.5 \%$, glucose $0.4 \%$ and triacylglycerol $2.7 \%$.

\section{Statistical analysis}

Data was analyzed using the Statistical Package for the Social Sciences (SPSS) software version 14.0 for Windows (SPSS Inc, Chicago, IL, U.S.). All area under the concentration verses time curve calculations were performed using the trapezoidal method. Student's $t$-tests for correlated data were used to assess differences between fasting and area under the curve values for acylated ghrelin, glucose, insulin, triacylglycerol and appetite perceptions between the control and exercise trials. 
Repeated measures, two-factor ANOVA was used to examine differences between the exercise and control trials over time for appetite, energy and macronutrient intake, acylated ghrelin, glucose, insulin and triacylglycerol. The Pearson product moment correlation coefficient was used to examine relationships between variables. Correction of values for changes in plasma volume did not alter the statistical significance of findings therefore for simplicity the unadjusted values are presented. Statistical significance was accepted at the 5\% level. Results are presented as mean \pm SEM. 


\section{Results}

\section{Exercise responses}

Participants completed the $90 \mathrm{~min}$ run at $10.3 \pm 0.3 \mathrm{~km} \cdot \mathrm{h}^{-1}$. This elicited a mean oxygen consumption equivalent to $68.8 \pm 0.8 \%$ of maximum oxygen uptake and generated a mean heart rate and net (exercise minus resting) energy expenditure of $173 \pm 3$ beats $\min ^{-1}$ and $5324 \pm 186 \mathrm{~kJ}(1273 \pm 45 \mathrm{kcal})$, respectively. A mean non-protein respiratory quotient of $0.89 \pm 0.01$ reflected the proportional contributions of carbohydrate and fat $(64 \pm 5 \%$ and $36 \pm 5 \%)$ to energy provision. A median RPE value of 15 indicated that the participants perceived the intensity of the run to be 'hard.'

\section{Baseline Parameters}

No between trial differences existed at baseline in the plasma concentrations of acylated ghrelin, glucose, insulin or triacylglycerol. Appetite perceptions were also no different at baseline (Table 2).

(Insert Table 2 near here)

\section{Appetite and energy intake}

Two-factor ANOVA revealed a main effect of time (all $P<0.001$ ) and a trial $\mathrm{x}$ time interaction (all $P<0.023$ ) for each appetite perception assessed (hunger, fullness, satisfaction and prospective food consumption) indicating that responses differed over time between the control and exercise trials (Figure 1). Post-hoc analysis indicated differences in hunger and prospective food consumption between the control and exercise trials at $0.5,1$ and $1.5 \mathrm{~h}$ indicating suppressed hunger and prospective food consumption during exercise (all $P<0.05$ ). Differences in ratings of fullness and 
satisfaction were apparent at 0.5 and $1 \mathrm{~h}$ (all $P<0.05$ ) demonstrating elevated perceptions during exercise. After adjustment for multiple comparisons using Bonferroni method none of these differences remained significant.

\section{(Insert Figure 1 near here)}

Two-factor ANOVA showed a significant difference in the amount of energy consumed at the separate meals during the course of the trials (main effect of time, $P<0.001$ ) however this differential was not influenced by the trial (Table 3). After accounting for the energy expenditure induced by exercise participants remained in energy deficit in the exercise trial as compared with the control trial (control $17191 \pm 1144 \mathrm{~kJ}(4109 \pm$ $273 \mathrm{kcal})$, exercise $12282 \pm 1252 \mathrm{~kJ}(2935 \pm 299 \mathrm{kcal}))$.

(Insert Table 3 near here)

\section{Macronutrient intake}

For fat, protein and carbohydrate intake two-factor ANOVA revealed a main effect of time $(P<0.001)$ indicating that the intake of these macronutrients varied across the meals within each trial. There was no significant difference in macronutrient intake between the exercise and control trials (Table 4).

(Insert Table 4 near here) 


\section{Plasma Metabolites}

Two-factor ANOVA revealed a significant main effect of trial $(P=0.009)$, time $(P<$ $0.001)$ and a significant interaction effect (trial x time $)(P<0.001)$ for plasma acylated ghrelin concentrations (Figure 2).

(Insert Figure 2 near here)

Post-hoc analysis using the Bonferroni method demonstrated between trial differences at 0.75 and $1.5 \mathrm{~h}$ indicating suppressed acylated ghrelin during and immediately after exercise. Relative to control, the acylated ghrelin area under the concentration verses time curve was significantly lower $(40 \%)$ over the first $2.5 \mathrm{~h}$ of the exercise trial (control $347 \pm 47$, exercise $\left.209 \pm 35 \mathrm{pg} \cdot \mathrm{mL}^{-1} \cdot 2.5 \mathrm{~h}\right)(P=0.002)$ and for the total $10 \mathrm{~h}$ (25\%) (control $934 \pm 129$, exercise $\left.697 \pm 115 \mathrm{pg} \cdot \mathrm{mL}^{-1} \cdot 10 \mathrm{~h}\right)(P=0.011)$. Area under the acylated ghrelin concentration verses time curve was not significantly different between trials after consumption of the first meal $(3.5-10$ h) (control $490 \pm 75$, exercise $418 \pm$ $\left.74 \mathrm{pg} \cdot \mathrm{mL}^{-1} \cdot 6.5 \mathrm{~h}\right)$. On the second day of trials fasting plasma acylated ghrelin was not significantly different between the control $\left(137 \pm 17 \mathrm{pg} \cdot \mathrm{mL}^{-1}\right)$ and exercise $(137 \pm 16$ $\left.\mathrm{pg} \cdot \mathrm{mL}^{-1}\right)$ trials.

Figure 3 shows the plasma glucose, triacylglycerol and insulin responses in the control and exercise trials. For plasma glucose two-factor ANOVA revealed a significant main effect of time $(P<0.001)$ and an interaction effect (trial $\mathrm{x}$ time $)(P<0.001)$. Post-hoc analysis indicated between trial differences at 2.5 and $6 \mathrm{~h}$ but after adjustment for multiple comparisons using the Bonferroni method these did not remain significant. For plasma triacylglycerol two-factor ANOVA yielded a significant main effect of trial $(P=$ 
0.036), time $(P<0.001)$ and a significant interaction (trial $\mathrm{x}$ time) effect $(P<0.001)$. Post-hoc analysis indicated between trial differences at 1.5, 5.5, 6, 6.5, 9 and $9.5 \mathrm{~h}$ but after adjustment for multiple comparisons using the Bonferroni method only the $1.5 \mathrm{~h}$ comparison remained significant. For plasma insulin concentrations two-factor ANOVA revealed a significant main effect of time $(P<0.001)$ but no trial or interaction (trial $\mathrm{x}$ time) main effects.

(Insert Figure 3 near here)

\section{Correlations between acylated ghrelin and other variables}

Fasting concentrations of plasma acylated ghrelin were inversely related to body weight $(r=-0.720, P=0.029)$ and tended to be negatively associated with BMI $(r=-0.611, P$ $=0.081)$. A significant inverse association was observed between insulin and acylated ghrelin area under the concentration verse time curve on the exercise trial in between the first and second meals $(2.5-5.5 \mathrm{~h})(r=-0.851, P=0.031)$. A tendency towards a significant inverse relationship was observed between plasma triacylglycerol and acylated ghrelin values in the exercise trial in-between the second and third meal (5.5 9 h) $(r=-0.663, P=0.052)$. At individual time points during the exercise trial acylated ghrelin was inversely related with triacylglycerol at $6.5 \mathrm{~h}(r=-0.675, P=0.046)$ and tended to be inversely related with insulin at $1.5 \mathrm{~h}(r=-0.808, P=0.052)$. On both the control and exercise trials no correlations were observed between plasma acylated ghrelin immediately prior to ad libitum meals and subsequent energy consumption. Moreover, no relationships were found between energy intake at each meal and the percentage change in plasma acylated ghrelin. 


\section{Discussion}

The purpose of this investigation was to examine appetite, food intake and plasma acylated ghrelin during and for an extended period after a prolonged bout of treadmill running which was sufficient to induce a substantial energy deficit. The primary findings are that exercise induced a brief suppression of appetite and plasma acylated ghrelin yet did not influence appetite, acylated ghrelin or ad libitum energy/macronutrient intake in the $22.5 \mathrm{~h}$ after.

During exercise perceptions of hunger and prospective food consumption were transiently suppressed while ratings of satisfaction and fullness were increased. These responses indicate an inhibition of appetite during exercise and this outcome is consistent with previous reports of exercise induced anorexia resulting from bouts of activity performed at moderate intensities or higher (> $60 \%$ of maximum oxygen uptake) (King, Burley, \& Blundell,1994; King \& Blundell, 1995). The mechanisms responsible for changes in appetite as a consequence of exercise are not well defined however the role of circulating concentrations of gut hormones have began to receive attention (Broom et al, 2007; 2009; Hagobian et al, 2009; Martins et al, 2007). Specifically, Broom et al (2007) reported data supporting a role of acylated ghrelin in determining suppressed ratings of hunger during $1 \mathrm{~h}$ of intense treadmill running (72.2\% of maximum oxygen uptake). The data from the present investigation support this notion as circulating concentrations of acylated ghrelin were significantly lower during and at the end of exercise. Despite this, the absence of any significant relationships between acylated ghrelin and markers of appetite questions this hypothesis. 
Changes in appetite diminished soon after exercise, remaining no different from control values over the course of the trial. This outcome was unexpected given the extreme energy deficit induced during exercise. It was thought that ratings of appetite would be higher at some point within the hours after exercise in an effort to stimulate a compensatory increase in energy intake. Indeed, heightened perceptions of hunger and desire to eat have been reported in two previous investigations which have examined the appetite response to exercise over an extended duration (Broom et al, 2007; Malkova, McLaughlin, Manthou, Wallace, \& Nimmo, 2008). The energy expenditure induced by exercise was greater in the present study therefore it remains unclear why a compensatory appetite response was not observed. Exercise duration was longer in this investigation therefore it is possible that this variable may be important in determining post-exercise appetite perceptions.

Ghrelin is an appetite stimulating hormone with an important role in the acute regulation of energy homeostasis (Cummings, 2006). Circulating concentrations ghrelin rise before meals and fall thereafter suggesting a role as a meal initiating signal (Cummings et al, 2001; Cummings, Frayo, Marmonier, Aubert, \& Chapelot, 2004). In both the short and long-term the diurnal profile of ghrelin is sensitive to changes in energy flux. An inverse relationship exists between the energy content of meals and the subsequent rise in ghrelin prior to the next meal (Leidy \& Williams, 2006). Moreover, chronic energy restriction through diet and exercise induces heightened circulating concentrations of ghrelin during the nocturnal period and at meal related ghrelin peaks (Leidy et al, 2007). Based on this, in the present study we postulated that the large energy deficit induced by exercise would stimulate a compensatory increase in acylated ghrelin in the hours after as a stimulus to increase appetite and energy intake. It is 
unclear why circulating acylated ghrelin concentrations were not elevated in the hours after exercise. Surprisingly, although not statistically different, values actually appeared lower after exercise compared with those observed during control and it is possible that this may have been implicated in the lack of compensation in energy intake. Differences in feeding responses are unlikely to be implicated as both energy and macronutrient intakes were similar between the exercise and control trials. It is possible that some exercise related factor may interfere in the metabolism of acylated ghrelin however the associated mechanisms are not known.

Despite exercise inducing a transient suppression of appetite and acylated ghrelin, energy intake at the first buffet meal after exercise was not significantly different between the exercise and control trials. Moreover, energy intake was also no different at any of the three other feeding opportunities provided during this investigation. This response confirms previous findings which have observed no change in energy intake during meals consumed within the hours after exercise (King et al, 1994; King \& Blundell, 1995) or on the day afterwards (King, Lluch, Stubbs, \& Blundell, 1997). Although we were aware of these findings no investigation has induced such an energy deficit during a single bout of exercise. It was thought that this stimulus may invoke a response in energy intake that had not been observed by previous researchers. It has been said that we eat not for today but the day before yesterday (Edholm, 1977). It is therefore possible that energy intake compensation may have occurred over a greater period of time however a longer period of observation would be needed to test this hypothesis. 
It is known that missing a meal or consuming a meal of reduced energy content results in elevated hunger and energy intake at the next opportunity (Hubert, King, \& Blundell, 1998). For the participants in this study the energy expended during exercise would have been greater than the energy content of a typical meal therefore it appears that a different homeostatic response is elicited when energy deficits are induced by dietary means as compared with exercise i.e. energy leaving the system verses a restriction on energy entering the system. Although findings in this area are contradictory, this outcome supports the use of exercise in weight management.

This study has some notable limitations. Firstly, the low number of participants examined may have constrained the ability to detect significant relationships between variables examined. Secondly, the exercise protocol used in this study was designed to be physically challenging in order to invoke a high level of energy expenditure. Consequently, the outcomes reported may not transfer to situations where typical volumes of exercise are performed. Finally, as previously mentioned, the $24 \mathrm{~h}$ observation period may not have been long enough to detect more delayed responses in the variables assessed. Further work is therefore required to examine these responses over a longer duration of time.

In conclusion, this study has shown that a 90 min bout of treadmill running induces a brief suppression of appetite and plasma acylated ghrelin, yet does not influence shortterm energy/macronutrient intake - despite inducing a substantial energy deficit. These outcomes contribute knowledge regarding the role of exercise in energy homeostasis. These findings indicate that exercise can induce substantial deficits in energy without 
eliciting compensatory responses in acylated ghrelin, appetite and energy intake that would render exercise futile in weight management.

\section{Acknowledgements}

We would like to thank the Great Britain Sasakawa Foundation for funding Dr Miyashita's travel and living expenses during the conduct of this study. We also wish to thank Miss Rosalind West, Miss Vicky Blair and Miss Swee-Lee Liew for their help with data collection and all of the volunteers for their participation in this study. JAK recruited the participants, supervised the data collection, assisted with all aspects of the biochemistry and performed the data analysis. MM and LKW assisted with data collection and the biochemical analysis. DJS performed the venous cannulations. DJS and JAK conceived the study and wrote the manuscript.

None of the authors had any conflict of interest regarding any aspect of this study. 


\section{References}

Blundell, J.E., \& King, N.A. (1999). Physical activity and regulation of food intake: current evidence. Medicine and Science in Sports and Exercise, 31, S573-583.

Blundell, J.E., Stubbs, R.J., \& Hughes, D.A., Whybrow, S., King, N.A. (2003). Cross talk between physical activity and appetite control: does physical activity stimulate appetite? Proceedings of the Nutrition Society, 62, 651-661.

Broom, D.R., Batterham, R.L., King, J.A., \& Stensel, D.J. (2009). Influence of resistance and aerobic exercise on hunger, circulating levels of acylated ghrelin, and peptide YY in healthy males. American Journal of Physiology: Regulative Integrative and Comparative Physiology, 296, R29-35.

Broom, D.R., Stensel, D.J., Bishop, N.C., Burns, S.F., \& Miyashita, M. (2007). Exercise-induced suppression of acylated ghrelin in humans. Journal of Applied Physiology, 102, 2165-2171.

Borg, G.A. (1973). Perceived exertion: a note on "history" and methods. Medicine and Science in Sports, 5, 90-93.

Broglio, F., Gottero, C., Prodam, F., Gauna, C., Mucciolo, G., Papotti, M., Aribat, T., \& Van Der Lely, A.J. (2004). Non-acylated ghrelin counteracts the metabolic but not the neuroenocrine response to acylated ghrelin in humans. Journal of Clinical Endocrinology and Metabolism, 89, 3062-3065. 
Callahan, H.S., Cummings, D.E., Pepe, M.S., Breen, P.A., Matthys, C.C., \& Weigle, D.S. (2004). Postprandial suppression of plasma ghrelin level is proportional to ingested caloric load but does not predict intermeal interval in humans. Journal of Clinical Endocrinology and Metabolism, 89, 1319-1324.

Catenacci, V.A., \& Wyatt, H.R. (2007). The role of physical activity in producing and maintaining weight loss. Nature Clinical Practice Endocrinology and Metabolism, 3, 518-529.

Cummings, D.E. (2006). Ghrelin and the short-and long-term regulation of appetite and body weight. Physiology and Behaviour, 89, 71-84.

Cummings, D.E., Frayo R.S., Marmonier, C., Aubert, R., \& Chapelot, D. (2004). Plasma ghrelin and hunger scores in humans initiating meals voluntarily without timeand food-related cues. American Journal of Physiology: Endocrinology and Metabolism, 287, E297-304.

Cummings, D.E., Purnell, J.Q., Frayo, R.S., Schmidova, K., Wisse, B.E., \& Weigle, D.S. (2001). A preprandial rise in ghrelin suggests a role in meal initiation in humans. Diabetes, 50, 1714-1719.

Dill, D.B., \& Costill, D.L. (1974). Calculation of percentage changes in volumes of blood, plasma, and red cells in dehydration. Journal of Applied Physiology, 37, 247248. 
Donnelly, J.E., Blair S.N., Jakicic, J.M., Manore, M.M., Rankin, J.W., \& Smith, B.K; American College of Sports Medicine. American College of Sports Medicine Position Stand. (2009). Appropriate physical activity intervention strategies for weight loss and prevention of weight regain for adults. Medicine and Science in Sports and Exercise, $41,459-471$.

Durnin, J.V.G.A., \& Wormersley, J. (1974). Body fat assessment from total body density and its estimation from skinfold thickness: measurements on 481 men and women aged from 16 to 72 years. British Journal of Nutrition, 32, 77-97.

Edholm, O.G. (1977). Energy balance in man. Journal of Human Nutrition, 1, 413-431.

Flint, A., Raben, A., Blundell, J.E., \& Astrup, A. (2000). Reproducibility, power and validity of visual analogue scales in assessment of appetite sensations in single test meal studies. International Journal of Obesity, 24, 38-48.

Frayn, K.N. (1983). Calculation of substrate oxidation rates in vivo from gaseous exchange. Journal of Applied Physiology, 55, 628-634.

Hagobian, T.A., Sharoff, C.G., Stephens, B.R., Wade, G.N., Silva, J.E., Chipkin, S.R., \& Braun, B. (2009). Effects of exercise on energy-regulating hormones and appetite in men and women. American Journal of Physiology: Regulative Integrative and Comparative Physiology, 296, R233-242. 
Hubert, P., King, N.A., \& Blundell, J.E. (1998). Uncoupling the effects of energy expenditure and energy intake: appetite response to short-term energy deficit induced by meal omission and physical activity. Appetite, 31, 9-19.

Kelly, T., Yang, W., Chen, C.S., Reynolds, K., \& He, J. (2008). Global burden of obesity in 2005 and projections to 2030. International Journal of Obesity, 32, 14311437.

King, N.A., \& Blundell, J.E. (1995). High fat foods overcome the energy expenditure induced by high intensity cycling or running. European Journal of Clinical Nutrition, $49,114-123$.

King, N.A., Burley, V.J., \& Blundell, JE. (1994). Exercise-induced suppression of appetite: effects on food intake and implications for energy balance. European Journal of Clinical Nutrition, 48, 715-724.

King, N.A., Caudwell, M., Hopkins, M., Byrne, N.M., Colley, R., Hills, A.P., Stubbs, J.R., \& Blundell, J.E. (2007). Metabolic and behavioural compensatory responses to exercise interventions: barriers to weight loss. Obesity, 15, 1373-1383.

King, N.A., Lluch, A., Stubbs, R.J., \& Blundell, J.E. (1997). High dose exercise does not increase hunger or energy intake in free living males. European Journal of Clinical Nutrition, 51, 478-483. 
Kraemer, R.R., \& Castracane, V.D. (2007). Exercise and humoral mediators of peripheral energy balance: ghrelin and adiponectin. Experimental Biology and Medicine, 232, 184-194.

Leidy, H.J., Dougherty, K.A., Frye, B.R., Duke, K.M., \& Williams, N.I. (2007). Twenty-four-hour ghrelin is elevated after calorie restriction and exercise training in non-obese women. Obesity, 15, 446-455.

Leidy, H.J., \& Williams, N.I. (2006). Meal energy content is related to features of mealrelated ghrelin profiles across a typical day of eating in non-obese premenopausal women. Hormone and Metabolic Research, 38, 317-322.

Liu, J., Prudom, C.E., Nass, R., Pezzoli, S.S., Oliveri, M.C., Johnson, M.L., Veldhuis, P., \& Gordan, D.A., Howard, A.D., Witcher, D.R., Getsen, H.M., Gaylinn, B.D, Thorner, M.O. (2008). Novel ghrelin assays provide evidence for independent regulation of ghrelin acylation and secretion in healthy young men. Endocrine Research, 93, 1980-1987.

Malkova, D., McLaughlin, R., Manthou, E., Wallace, A.M., \& Nimmo, M.A. (2008). Effect of moderate-intensity exercise session on preprandial and postprandial responses of circulating ghrelin and appetite. Hormone and Metabolic Research, 40, 410-415.

Maraki, M., Tsofliou, F., Pitsiladis, Y.P., Malkova, D., Mutrie, N., \& Higgins, S. (2005). Acute effects of a single exercise class on appetite, energy intake and mood. Is there a time of day effect? Appetite, 45, 272-278. 
Martins, C., Morgan, L.M., Bloom, S.R., \& Robertson, M.D. (2007). Effects of exercise on gut peptides, energy intake and appetite. Journal of Endocrinology, 193, 251-258.

Martins, C., Morgan, L., \& Truby, H. (2008). A review of the effects of exercise on appetite regulation: an obesity perspective International Journal of Obesity, 32, 13371347.

Marzullo, P., Salvadori, A., Brunani, A., Verti, B., Walker, G.E., Fanari, P., Tovaglieri, I., De Medici, C., Savia, G., \& Liuzzi A. (2008). Acylated ghrelin decreases during acute exercise in the lean and obese state. Clinical Endocrinology (Oxf), 69, 970-971.

Murphy, K.G., \& Bloom., S.R. (2006). Gut hormones and the regulation of energy homeostasis. Nature, 444, 854-859.

Seagle, H.M., Strain, G.W., Makris, A., \& Reeves, R.S; American Dietetic Association. (2009). Position of the American Dietetic Association: weight management. Journal of the American Dietetic Association, 109, 330-346.

Siri, W.E. (1956). The gross composition of the body. Advances in Biology and Medical Physics, 4, 239-280.

Taylor, H.L., Buskirk, E., \& Henschel, A. (1955). Maximum oxygen intake as an objective measure of cardio-respiratory performance. Journal of Applied Physiology, 8, 73-80. 
Ueda, S., Yoshikawa, T., Katsura, Y., Usui, T., Nakao, H., Fujimoto, S. (2009). Changes in gut hormones levels in negative energy balance during aerobic exercise in obese young males. Journal of Endocrinology, 201, 151-159. 
Table 1: Characteristics of the participants $(n=9)$. Values are mean \pm SEM.

\begin{tabular}{cll}
\hline Characteristic & & \\
\hline Age $(\mathrm{y})$ & $22.2 \pm 0.8$ \\
BMI $\left(\mathrm{kg} \cdot \mathrm{m}^{-2}\right)$ & $23.6 \pm 0.4$ \\
Body Mass $(\mathrm{kg})$ & $77.5 \pm 2.3$ \\
Body Fat $(\%)$ & $17.8 \pm 1.7$ \\
Maximum oxygen uptake $\left(\mathrm{ml} \cdot \mathrm{kg}^{-1} \cdot \mathrm{min}^{-1}\right)$ & $60.5 \pm 1.5$ \\
\hline
\end{tabular}


Table 2: Baseline hormones/metabolites and appetite values in the control and exercise trials. Values are mean $\pm \operatorname{SEM}(n=9)$. PFC $=$ prospective food consumption.

\begin{tabular}{crrrrrrc}
\hline & \multicolumn{2}{c}{ Control } & \multicolumn{2}{c}{ Exercise } & $P$ \\
\hline Acylated Ghrelin $\left(\mathrm{pg} \cdot \mathrm{mL}^{-1}\right)$ & 147.1 & \pm & 19.7 & 130.3 & \pm & 15.1 & 0.103 \\
Glucose $\left(\mathrm{mmol} \cdot \mathrm{L}^{-1}\right)$ & 5.10 & \pm & 0.05 & 5.07 & \pm & 0.12 & 0.766 \\
Insulin $\left(\mathrm{pmol} \cdot \mathrm{L}^{-1}\right)$ & 24.3 & \pm & 2.5 & 29.5 & \pm & 5.4 & 0.403 \\
Triacylglycerol $\left(\mathrm{mmol} \cdot \mathrm{L}^{-1}\right)$ & 0.90 & \pm & 0.11 & 0.79 & \pm & 0.08 & 0.200 \\
Hunger $(0-100)$ & 65 & \pm & 8 & 74 & \pm & 5 & 0.169 \\
Satisfaction $(0-100)$ & 22 & \pm 5 & 19 & \pm & 5 & 0.405 \\
Fullness $(0-100)$ & 17 & \pm & 6 & 16 & \pm & 4 & 0.765 \\
PFC (0-100) & 77 & \pm & 7 & 78 & \pm & 5 & 0.858 \\
\hline
\end{tabular}


Table 3: Energy intake during the control and exercise trials. Values are mean \pm SEM ( $n$ $=9), \mathrm{kJ}$ and (kcal).

\begin{tabular}{ccccc}
\hline & & Control & Exercise & $\boldsymbol{P}$ \\
\hline Cold Meal & kJ & $6879 \pm 700$ & $6165 \pm 700$ & \\
$(2.5-3 \mathrm{~h})$ & $($ kcal $)$ & $(1644 \pm 167)$ & $(1474 \pm 167)$ & 0.351 \\
Hot Meal & kJ & $4553 \pm 621$ & $4928 \pm 618$ & \\
$(5.5-6 \mathrm{~h})$ & $(\mathbf{k c a l})$ & $(1088 \pm 148)$ & $(1178 \pm 148)$ & 0.602 \\
Cold Meal & kJ & $4694 \pm 341$ & $5214 \pm 623$ & \\
$(9-9.5 \mathrm{~h})$ & $(\mathbf{k c a l})$ & $(1122 \pm 101)$ & $(1246 \pm 149)$ & 0.291 \\
Overnight & kJ & $1065 \pm 275$ & $1299 \pm 299$ & \\
$(10-15$ h) & $($ kcal $)$ & $(255 \pm 66)$ & $(310 \pm 71)$ & 0.410 \\
Total Trial & kJ & $17191 \pm 1144$ & $17606 \pm 1384$ & \\
$(0-24$ h) & $($ kcal $)$ & $(4109 \pm 273)$ & $(4208 \pm 331)$ & 0.532 \\
\hline
\end{tabular}


Table 4: Macronutrient intake in the control (upper panel) and exercise (lower panel) trials. Values are mean $\pm \operatorname{SEM}(n=9)$.

\begin{tabular}{ccccc}
\hline Control Trial & & Fat & Carbohydrate & Protein \\
\hline Cold Meal & Grams & $56 \pm 7$ & $220 \pm 30$ & $65 \pm 12$ \\
$(2.5-3 \mathrm{~h})$ & $(\%)$ & $(30.7)$ & $(53.6)$ & $(15.7)$ \\
Hot Meal & Grams & $12 \pm 2$ & $221 \pm 31$ & $24 \pm 4$ \\
$(5.5-6 \mathrm{~h})$ & $(\%)$ & $(9.9)$ & $(81.2)$ & $(8.9)$ \\
Cold Meal & Grams & $40 \pm 5$ & $140 \pm 12$ & $50 \pm 5$ \\
$(9-9.5$ h) & $(\%)$ & $(31.5)$ & $(50.0)$ & $(18.5)$ \\
Overnight & Grams & $5 \pm 2$ & $49 \pm 12$ & $3 \pm 1$ \\
$(10-15$ h $)$ & $(\%)$ & $(17)$ & $(78.5)$ & $(4.5)$ \\
Total Trial & Grams & $113 \pm 10$ & $630 \pm 49$ & $143 \pm 16$ \\
$(0-24$ h $)$ & $(\%)$ & $(24.7)$ & $(61.3)$ & $(14.0)$ \\
\hline
\end{tabular}

\begin{tabular}{ccccc}
\hline Exercise Trial & & Fat & Carbohydrate & Protein \\
\hline Cold Meal & Grams & $46 \pm 7$ & $205 \pm 27$ & $59 \pm 7$ \\
$(2.5-3 \mathrm{~h})$ & $(\%)$ & $(28.1)$ & $(55.3)$ & $(16.6)$ \\
Hot Meal & Grams & $15 \pm 3$ & $232 \pm 29$ & $29 \pm 4$ \\
$(5.5-6$ h $)$ & $(\%)$ & $(11.1)$ & $(78.9)$ & $(10)$ \\
Cold Meal & Grams & $45 \pm 6$ & $150 \pm 22$ & $60 \pm 10$ \\
$(9-9.5$ h) & $(\%)$ & $(32.6)$ & $(48.1)$ & $(19.3)$ \\
Overnight & Grams & $8 \pm 2$ & $56 \pm 13$ & $4 \pm 1$ \\
$(10-15$ h) & $(\%)$ & $(22.4)$ & $(72.7)$ & $(4.9)$ \\
Total Trial & Grams & $114 \pm 12$ & $643 \pm 56$ & $152 \pm 14$ \\
$(0-24$ h) & $(\%)$ & $(24.1)$ & $(61.2)$ & $(14.7)$ \\
\hline
\end{tabular}




\section{Figure Legends}

Figure 1: Perceptions of hunger (a), satisfaction (b), prospective food consumption (c) and fullness $(\mathrm{d})$ in the control $(\bullet)$ and exercise $(\circ)$ trials. Values are mean $\pm \operatorname{SEM}(n=$ 9). Black rectangle indicates running, diagonally shaded rectangles indicate cold meals, hatched shaded rectangle indicates the hot meal.

Figure 2: Plasma concentration of acylated ghrelin in the control $(\bullet)$ and exercise $(\circ)$ trials. Values are mean \pm SEM $(n=9)$. Black rectangle indicates running, diagonally shaded rectangles indicate cold meals, hatched shaded rectangle indicates the hot meal. *Significantly different between trials after Bonferroni adjustment $(P<0.0045)$.

Figure 3: Plasma concentrations of triacylglycerol (a), insulin (b) and glucose (c) in the control $(\bullet)$ and exercise $(\circ)$ trials. Values are mean \pm SEM $(n=9)$. * Significantly different from control after Bonferroni adjustment $(P=0.0042)$. Black rectangle indicates running, diagonally shaded rectangles indicate cold meals, hatched shaded rectangle indicates the hot meal. 


\section{Appendices}

Appendix A: Buffet items available at the cold buffet meals.

\begin{tabular}{|c|}
\hline Cereals (3 varieties) \\
\hline Milk \\
\hline White Bread \\
\hline Brown Bread \\
\hline Cheddar Cheese \\
\hline Ham \\
\hline Tuna \\
\hline Salted Crisps \\
\hline Mayonnaise \\
\hline Butter \\
\hline Margarine \\
\hline Apple \\
\hline Orange \\
\hline Banana \\
\hline Chocolate Rolls \\
\hline Muffins \\
\hline Cookies \\
\hline Nutri-grain bars \\
\hline Chocolate bar \\
\hline Pain au chocolate \\
\hline
\end{tabular}

Appendix B: Buffet items available at hot buffet meals.

\begin{tabular}{|c|}
\hline Rice - Pasta \\
\hline Sweet \& Sour Sauce - Tomato Sauce - Curry Sauce \\
\hline Naan bread - Bread Rolls \\
\hline Ice cream - Yoghurt - Tinned Mixed Fruit \\
\hline
\end{tabular}


Figure 1.
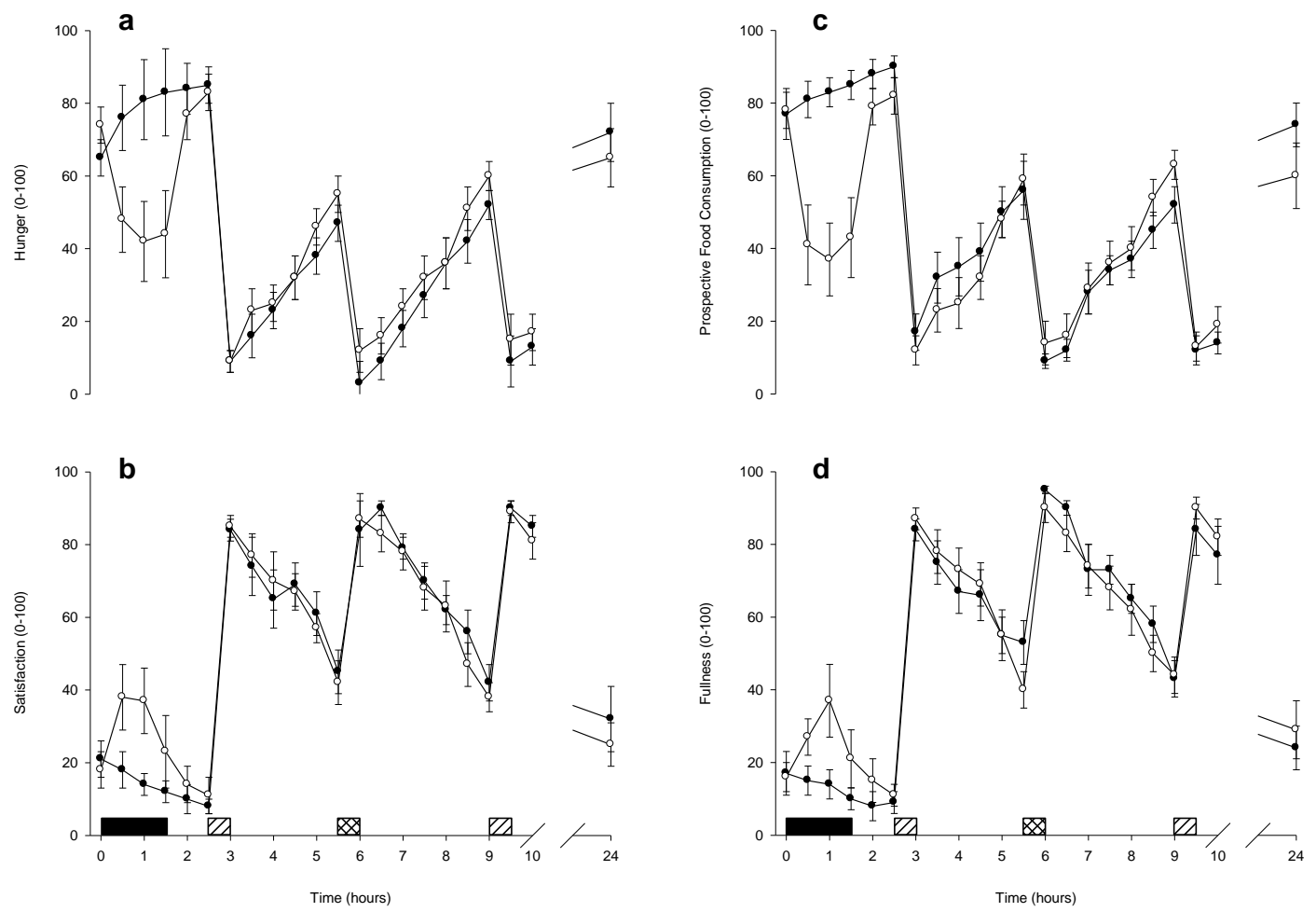
Figure 2.

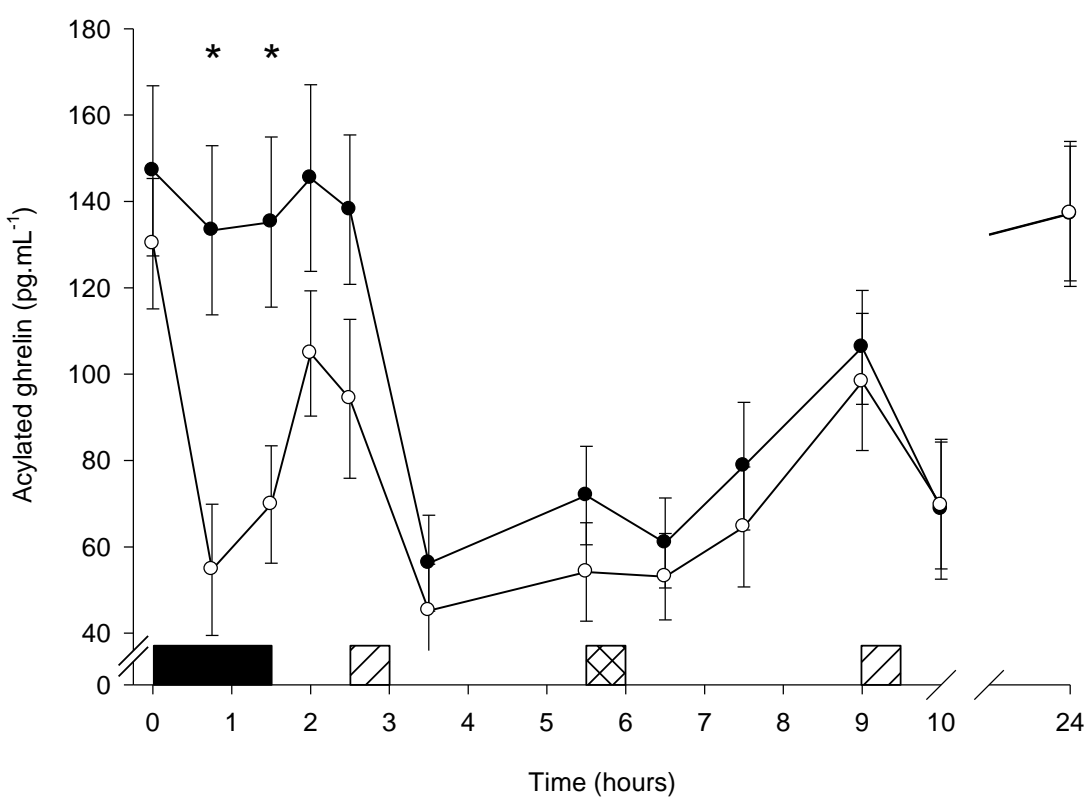


Figure 3.
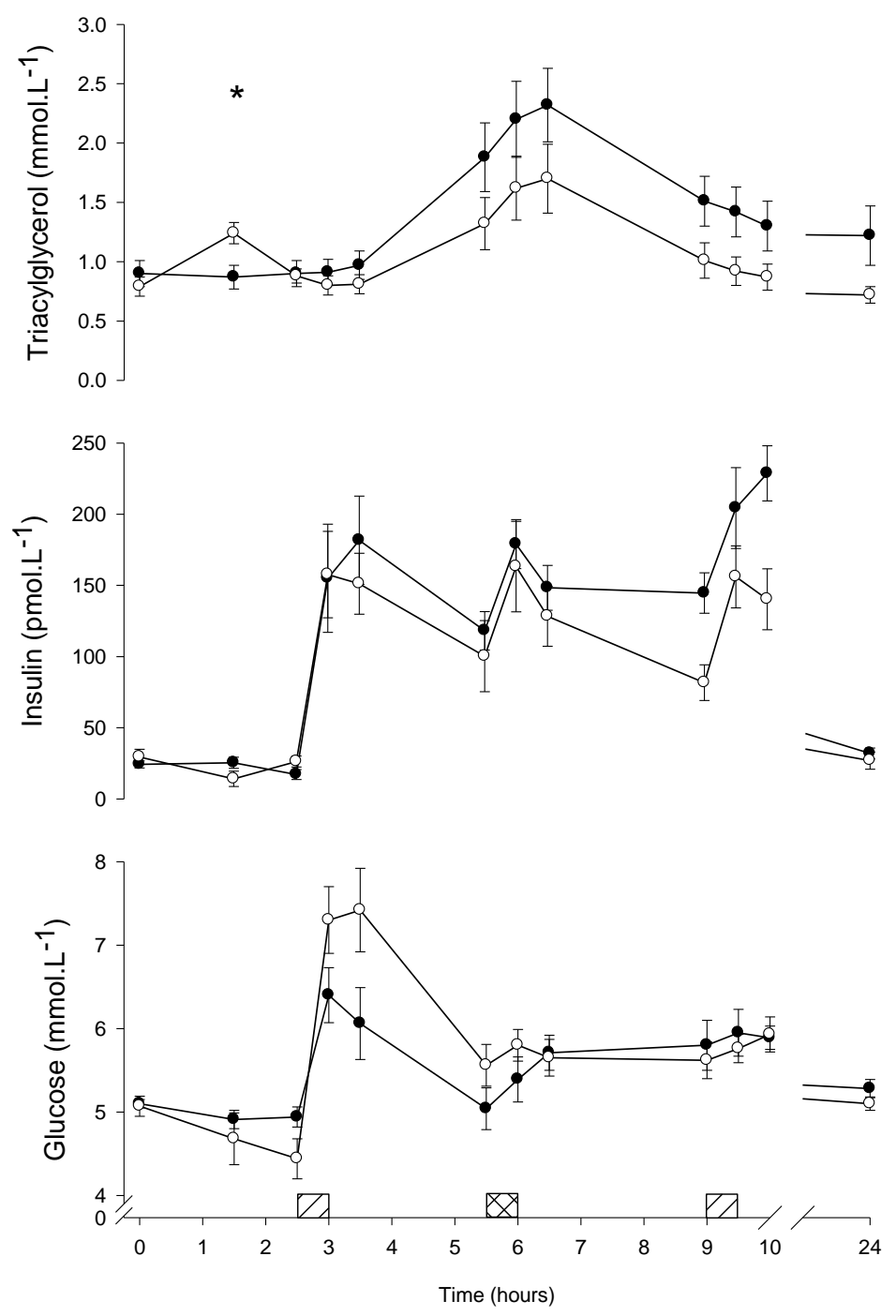
We have completed the author declaration on the first submission of this manuscript.

David Stensel

D.J.Stensel@lboro.ac.uk

14 December 2009 